\title{
Hearing Impairment in children with history of kernicterus and crebral palsy
}

\author{
Meena Maruti Ohal
}

\author{
Assistant Professor, Dept. of ENT, Annaporna Medical College and Hospital, Salem, Tamil Nadu, India
}

Corresponding Author: Meena Maruti Ohal

Email: feb15lov@yahoo.co.in

\begin{abstract}
Introduction: Critical period of development of speech and language is early 3 yrs of life. Even a mild hearing impairment can interfere with speech and language development. Hearing impairment has the highest incidence rate for any pediatric disability, since several risk factors in infants with cerebral palsy $(\mathrm{CP})$ are the same risk factors to develop hearing impairment. Thus, it should come as no surprise that hearing impairment occurs more frequently among children with cerebral palsy than in the general population. Recent studies have shown that up to $13 \%$ of children with cerebral palsy suffer from a hearing loss and important cause of auditory neuropathy.

Aim of the study: To assess and analyze the audiological profile in children with cerebral palsy Materials and Methods: A prospective study was done on 67 children of 1 to 16 years of age of both genders who were diagnosed with cerebral palsy. Tympanometry, otoacoustic emission, and auditory brain stem response hearing tests were employed to categorize the hearing impairment.

Results: Hearing impairment was observed in right ear $67.2 \%$ and left ear $64.2 \%$ in children with cerebral palsy. Profound sensorineural hearing loss in $25.4 \%$ in bilateral ear was observed. History of kernicterus was found in $17.9 \%$ children with cerebral palsy.

Conclusions: Prevalence of hearing impairment in children with cerebral palsy is alarming. This warrants early identification and diagnosis of hearing impairment. This early identification may facilitate better development of speech and language as well as positive outcomes. Therefore audiological assessment should be incorporated into the diagnostic and therapeutic plan of all children with cerebral palsy
\end{abstract}

Keywords: Hearing Loss, Cerebral palsy, BERA, Kernicterus

\section{Introduction}

Cerebral palsy was first described in 1862 by an orthopedic surgeon named William James Little. ${ }^{1}$ Cerebral palsy is a condition caused by damage to the brain, usually occurring before, during or shortly after birth. 'Cerebral' refers to the brain and 'palsy' refers to a disorder of movement or posture. Cerebral palsy is a central nervous system(CNS) disorder of movement, coordination, and posture, reflecting a nonprogressive abnormality or insult to the immature brain., ${ }^{2,3}$ Cerebral palsy is neither progressive nor communicable. It is also not curable, although education, therapy and applied technology can help people with CP lead productive lives. Children with $\mathrm{CP}$ have an organic complication in the peripheral and central nervous systems. ${ }^{4}$ However of hearing impairment are amenable to the treatment and rehabilitation strategies if identified at an early age and effective intervention program can be initiated.. Hearing impairment estimates as high as one third population of cerebral palsy, study done by Susan et al shows $4 \%$ to $13 \%$ hearing loss in children with $\mathrm{CP} .{ }^{5}$ Thus, overall future and success of a child can be improved by reducing the complications of hidden disability of hearing impairment
The hearing rehabilitation in children with cerebral palsy was studied by Melo et al said that currently there is still a controversy in cochlear implant centers regarding the indication of Cochlear implantation in cerebral palsy children. Those in favour of implantation theorize that minimizing auditory sensory deprivation can improve language and comprehension, and consequently the quality of life after cochlear implantation in this children and recommended cochlear implantion. ${ }^{6}$

However, there is less no data is available in the developing country like Indian context, with regards to the degree, and type of hearing impairment in children with cerebral palsy. The study was done to find the presence of hearing impairment in children with cerebral palsy. Our aim is to increase the awareness of possible correctable audiological impairment that hinder development and learning in children with cerebral palsy and timely intervention can be taken.

\section{Material and Methods}

A total of 67 children in the age range of 6 month to 16 years diagnosed with $\mathrm{CP}$ were selected for the study. The subjects were referred to ENT OPD for hearing evaluation or visited as follow-up during 
October 2017 and March 2018. The parental interview was conducted to obtain demographic information includes detailed history and examination with focus on prenatal, natal, postnatal history,etiology for Ceberal palsy and to find risk factors for CP. Audiological evaluation of this children was done using Otomicroscopy, Behavior observation audiometry(BOA), Otoacoustic Emission(OAE), Tympanometry, Pure Tone Audiometry(PTA) or Brainstem Evoked Response Audiometry(BERA).

\section{Statistical analysis}

Descriptive analysis of demographics and audiological test findings was carried out to determine the prevalence and to categorize the different types and degree of hearing impairment.

Result we studied 67 children with cerebral palsy, hypotonic type 14(20\%), 33(49.2\%) spastic, 13(19.4 $\%)$ dystonic and mixed $7(10 \%)$ Majority of the subjects were males; 44(65.7\%). The mean age of the study group was 2.9 years. The age group below 5 yrs was $52(77.7 \%)$. The youngest child in the study was 9 months old and oldest child being 14 years old. Consanguinity of marriage between the parents was studied. In the present study non-consanguineous marriages were $58(86.6 \%)$ and consanguineous marriages between parents were $9(13.4 \%)$. On birth history record the cerebral palsy children were born full term baby $55(82.2 \%)$ and $44(65.7 \%)$ were with normal birth weight and 39(58.2\%) cried immediately at birth. Out of 67 children on post natal History of kernicterus was found in $17.9 \%$ children with cerebral palsy.Behavioral observation audiometry result showed 25(37.3\%) had hearing loss and 42(62.7.8\%) had normal hearing. Otoacoustic Emissions findings in this study showed Out of 67 children right ear OAE were absent in $37(55.2 \%)$ ears and present in $16(23.9 \%)$ ears and not done in 14(20.9). Left ear OAE result show absent in $34(50.7 \%)$ and present in $19(28.4 \%)$ not done in 14(20.9). The findings on Brain Evoked Response Audiometry(BERA) showed out of 67 children examined for BERA on right ear $22(32.8 \%)$ had normal hearing, $7(10.4 \%)$ had minimal loss, $5(7.5 \%)$ had mild hearing loss, moderate hearing loss in $8(11.9 \%$ ) ears, moderately severe in not seen, severe in $4(6 \%)$ ears, profound in $17(25.4 \%)$ ears and not done in $4(6 \%)$ ear. BERA on left ear 24(35.8\%) had normal hearing, 5(7.5\%) had minimal loss, $7(13.6 \%)$ had mild hearing loss, moderate hearing loss in $7(10.4 \%)$ ears, severe in $3(4.5 \%)$, profound in $17(25.4 \%)$ ears and not done in $4(6 \%)$ ears. Findings of Tympanometry were Out of 67 children with cerebral palsy on right ear A type curve, 41(61.2\%) B type curve in $4(6.0 \%)$ and $14(20.9 \%)$ have $\mathrm{C}$ type curve. Out of 67 children with cerebral palsy on left ear A type curve, $42(62.7 \%)$ B type curve in 3(04.5\%) and $3(20.9 \%)$ have $\mathrm{C}$ type curve.

\section{Discussion}

$\mathrm{CP}$ consists of a heterogeneous group of nonprogressive clinical syndromes that are characterized by motor and postural dysfunction due to the damage to developing brain. A concomitant disability such as hearing impairment often exits with CP. The coexistence of unidentified hearing impairment can affect the treatment plan and longterm outcome of $\mathrm{CP}$. Therefore, an understanding of the interaction of the motor components and associated deficits in children with $\mathrm{CP}$ is necessary for setting comprehensive and realistic goals and better outcomes The crossectional observational study was done in tertiary care center from october 2017 to March 2018 to find the clinical and audiological profile of children with cerebral palsy attending to otorhinolaryngology out patient department after obtaining consent of the parents. Various studies have attempted to establish an association between cerebral palsy and hearing loss, most of this studies being from developed countries. The commonest type of cerebral palsy was spastic type, which was similar to studies done by Chitra et al and Pratiba et al. ${ }^{7,8}$

Moralis et al studied 64 children with cerebral palsy and found $60 \%$ sensorineural hearing loss. ${ }^{9}$ Zafeiriour et al studied hearing in children using brainstem evoked response in spastic cerebral palsy children and found $22 \%$ had abnormal finding in brain stem evoked audiometry. ${ }^{10}$

Our data differ from Morales et al. who stated prevalence of $60 \%$ hearing impairment among $\mathrm{CP},{ }^{8}$ whereas our data had similar result as Odding and Roebroech Hendrik etal reported 25\% incidence of hearing impairment in cerebral-palsied population. ${ }^{11}$ The differences in frequency of hearing impairment in $\mathrm{CP}$ in these studies may due to the variations in types of CP in each case study and/or the variable causes of $\mathrm{CP}$ in these cases.

The highest number of children with $\mathrm{CP}$ found to have sensorineural hearing impairment followed by conductive and mixed type of hearing impairment that can be accounted for damage to the growing brain and compounded with the associated problems such as poor body growth, oral-aural hygiene, and frequent 
cold and cough. All children who have hearing impairment exhibited defective speech and language skills.

\section{Type of Study}

A prospective Observational, descriptive study

\section{Period of Study}

March 2017 to March 2018

\section{Institute of Study}

Christian Medical College, Vellore, Tamil Nadu

\section{Financial support and sponsorship}

None.

\section{Conflicts of interest}

There are no conflicts of interest

\section{Reference}

1. Shevell MI, Bodensteiner JB Cerebral palsy: defining the problem. Semin Pediatr Neurol 2004;11(1):2-4.

2. Jones MW, Morgan E, Shelton JE. Primary care of the child with cerebral palsy: a review of system(Part II). Pediatr Health Care 2007;21:226-37.

3. Morris C. Definition and classification of cerebral palsy: A historical perspective. Dev Med Child Neurol Suppl 2007;109:3-7.
4. Ghai OP, editor. Central nervous system. In: Essentials Pediatrics. $6^{\text {th }}$ edn. New Delhi: CBS Publishers; 2004:540

5. Reid SM,| Modak MB, Berkowitz R, A population-based study and systematic review of hearing loss in children with cerebral palsy. Devel Med Child Neurol 2011,53:1038-45.

6. Anacléia Melo da Silva Hilgenberg, Hearing rehabilitation in cerebral palsy: development of language and hearing after cochlear implantation. Braz J Otorhinolaryngol 2005;48(2):494-500.

7. Sankar C and Mundkur N, Cerebral Palsy-Definition, Classification, Etiology and early Diagonosis. Indian J Pediatr 72:2005

8. Singhi $\mathrm{P}$, Changes in the Clinical Spectrum of Cerebral Palsy over Two Decades in North India-An Analysis of 1212 Cases. J Trop Pediatr 2013;59(6).

9. Angulo M C, Blanco A N, Terán G J, Aledo G A, Quintela R J. Sensorineural hearing loss in cerebral palsy patients. Acta Otorrinolaringol Esp 2006;57(7):3002.

10. Zafeiriou DI, Andreou A, Karasavidou K. Utility of brainstem auditory evoked potentials in with spastic cerebral palsy. Acta Paediatr 2000;89:194-7.

11. Odding EM, Hendrik R. The epidemiology of cerebral palsy, incidence, impairment and risk factors. Disabil Rehabil 2006;28:183-91.

How to cite: Ohal MM. Hearing Impairment in children with history of kernicterus and Cerebral palsy. IP J Otorhinolaryngol Allied Sci 2020;3(1):7-9. 